\title{
Peran Aktif NGO Humana dalam Memfasilitasi Pen- didikan Anak-Anak Tenaga Kerja Indonesia (TKI) di Sabah Malaysia
}

\author{
Muhammad Muyamin \\ Universitas Indonesia
}

\begin{abstract}
This paper explains why Humana, as a Non-Governmental Organization (NGO), provides education to children from Indonesian Migrant Workers (TKI) in Sabah Malaysia. Humana as an NGO in Malaysia has been provided education for marginalized children in Sabah. In fact, Indonesia has given attention to the education of TKI's children in Sabah. However, Humana continues to provide education services to TKI's children in Sabah. Humana has a reason to keep up on this issue. This paper collects data from the Indonesian government, including Indonesian Embassy in Malaysia, and the NGO Humana. This paper finds that Humana has a basic idea that encourages targets and goals which in turn provides education for TKI's children in Sabah.
\end{abstract}

Keywords: education, Indonesian Migrant Workers, NGO, Humana

\begin{abstract}
Abstrak
Tulisan ini menjelaskan tentang alasan NGO Humana memberikan pelayanan pendidikan terhadap anak-anak dari Tenaga Kerja Indonesia (TKI) di Sabah Malaysia. Humana sebagai NGO di Malaysia telah berperan dalam memberikan pendidikan anak-anak termarjinalkan di Sabah. Pemerintah Indonesia sebenarnya telah memberikan perhatian terhadap pendidikan anak-anak TKI di Sabah. Namun, Humana tetap memberikan pelayanan pendidikan kepada anak-anak TKI di Sabah. Humana tentu memiliki alasan untuk tetap berperan dalam isu pendidikan anak-anak TKI di Sabah. Tujuan dari tulisan ini adalah mengetahui hal yang melatarbelakangi Humana sebagai NGO di Malaysia memberikan pelayanan pendidikan anak-anak Indonesia di Sabah. Tulisan ini mengumpulkan data-data dari pemerintah Indonesia, Kedutaan Besar Republik Indonesia di Malaysia, serta NGO Humana. Hasil dari analisis pada tulisan ini menunjukkan bahwa Humana memiliki ide dasar yang kemudian mendorong adanya target dan tujuan kemudian berperan aktif dalam memberikan pelayanan pendidikan kepada anak-anak TKI di Sabah.
\end{abstract}

Kata-kata kunci: pendidikan, Tenaga Kerja Indonesia, NGO, Humana 


\section{Pendahuluan}

Artikel ini bertujuan untuk menjelaskan ide yang membentuk NGO dalam memberikan pelayanan pendidikan. Secara khusus, artikel ini menjelaskan ide dari NGO Humana dalam memberikan pendidikan untuk anak-anak TKI di Sabah. Ide ini yang kemudian mendorong adanya tujuan dan target dari Humana dalam memberikan fasilitas pendidikan untuk anak-anak TKI di Sabah. Selain itu, anak-anak TKI ini tidak terbatas hanya pada TKI yang legal, tetapi juga anak-anak TKI yang tidak memiliki dokumen resmi sehingga kehilangan hak dalam memperoleh pendidikan.

Globalisasi telah menyebabkan dampak besar bagi perekonomian suatu negara. Di sisi lain, globalisasi telah menimbulkan dampak negatif bagi masyarakat. Ketidakmerataan distribusi pendapatan terjadi akibat tidak berimbangnya kesempatan dan lapangan pekerjaan antara wilayah pedesaan dan perkotaan. Ketimpangan ini tampak jelas pada kebutuhan tenaga kerja dibandingkan dengan kemampuan penyerapan tenaga kerja. Kemiskinan, tuntutan ekonomi yang mendesak dan berkurangnya peluang serta penghasilan di bidang pertanian yang tidak memberikan suatu hasil yang tepat dan rutin dan adanya kesempatan untuk bekerja di bidang industri telah memberikan daya tarik yang kuat bagi tenaga kerja.

Masalah ketenagakerjaan adalah salah satu permasalahan yang menjadi perhatian di Indonesia, karena tidak hanya menyangkut pengangguran, tetapi juga masalah ekonomi, sosial bahkan politik dan keamanan. Keterbatasan lapangan pekerjaan seringkali membuat perbedaan antara pencari kerja dan lahan yang tersedia tidak sesuai. Hal ini pada akhirnya membuat jumlah pengangguran meningkat yang pada gilirannya mendorong tingginya angka kriminalitas dikarenakan orangorang akan melakukan segala cara untuk bertahan hidup. Gambar di bawah ini menunjukkan korelasi antara jumlah pengangguran dan tingkat kriminalitas.

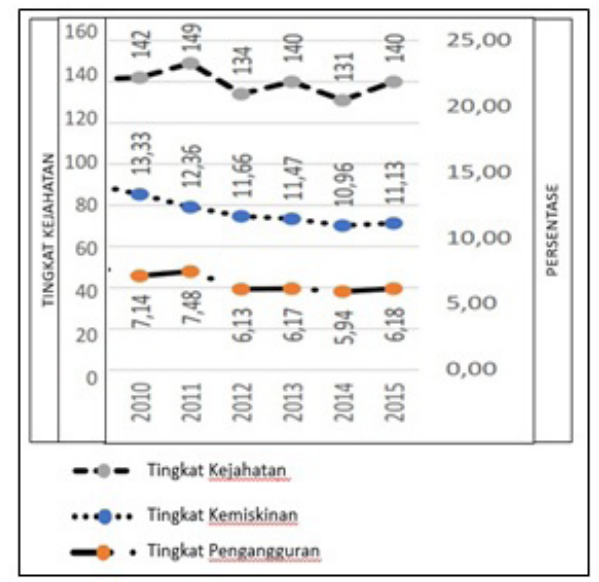


Keterbatasan lapangan pekerjaan di dalam negeri membuat sebagian orang mencari alternatif untuk mencari pekerjaan di luar negeri. Keterbatasan keterampilan yang dimiliki sebagian masyarakat Indonesia membuat pekerjaan yang dipilih adalah pekerjaan yang hanya mengandalkan kekuatan tubuh seperti pekerjaan rumah tangga, buruh pabrik, buruh di perkebunan dan pekerjaan kasar lainnya. Mereka biasa disebut sebagai Tenaga Kerja Indonesia (TKI), dan karena berpindah dari satu negara ke negara lain maka sering juga disebut sebagai buruh migran. Berdasarkan data dari Badan Nasional Penempatan dan Perlindungan Tenaga Kerja Indonesia (BNP2TKI) tahun 2017, Malaysia masih menjadi negara favorit tujuan para TKI untuk mengadu nasib di luar negeri dengan jumlah total 88.991 orang. Jumlah ini belum termasuk pekerja ilegal yang jumlahnya mencapai dua juta orang. Setelah itu, tempat yang menjadi tujuan para TKI berdasarkan data tahun 2017 adalah Hongkong dengan jumlah 68.103 serta Taiwan dengan jumlah 62.823 orang (BNP2TKI, 2018). Hal ini dikarenakan secara geografis wilayah Indonesia dan Malaysia sangat dekat. Letak geografis ini menjadi pertimbangan utama para TKI dalam memilih Malaysia sebagai negara tujuan.

Jumlah TKI yang besar di Malaysia mendorong adanya dampak negatif bagi TKI termasuk anak-anak TKI yang mengikuti orang tuanya merantau. Dampak negatif ini seperti hilangnya hak memperoleh pendidikan dan fasilitas kesehatan yang layak. Dampak negatif bagi anakanak TKI ini terjadi terutama pada mereka di wilayah Sabah dan Serawak yang masih masuk dalam wilayah Malaysia. Selain itu, dampak negatif bagi TKI didorong oleh ketidaklengkapan dokumen yang dimiliki untuk bekerja di negara lain. Kebanyakan TKI yang bekerja di Malaysia adalah mereka yang tidak memiliki dokumen lengkap. TKI yang tidak memiliki dokumen lengkap ini dapat disebut sebagai TKI ilegal. Dengan adanya TKI ilegal ini semakin mendorong terjadinya dampak negatif bagi TKI itu sendiri.

Pemerintah Indonesia dan Malaysia melakukan pertemuan untuk menyepakati layanan pendidikan bagi anak-anak TKI di Sabah, Malaysia. Pertemuan tersebut menghasilkan kesepakatan berupa pendirian Sekolah Indonesia Kota Kinabalu (SIKK) pada tahun 2008 yang menjadi induk bagi Community Learning Center (CLC) yang saat ini jumlahnya ratusan. Selain SIKK dan CLC nya terdapat Non Govermental Organization (NGO) yang juga mempunyai peran dalam melayani pendidikan anak-anak Indonesia di Sabah. NGO tersebut adalah Humana Child Aid Society yang juga melayani pendidikan anak-anak Indonesia di Sabah. Meskipun Indonesia sudah secara resmi memiliki SIKK dan CLC dalam melayani pendidikan dan diakui oleh Malaysia, Humana tetap berusaha dalam memberikan pelayanan pendidikan bagi anak-anak Indonesia di Sabah. Oleh karena 
itu, muncul pertanyaan mengapa Humana melayani pendidikan anakanak Indonesia di Sabah meskipun sudah terdapat SIKK dan CLC yang memberikan pelayanan tersebut?

Sudah cukup banyak penelitian yang membahas kerjasama Indonesia dan Malaysia dalam menangani pendidikan TKI. Penelitian Handayani (2014) membahas kerjasama Indonesia-Malaysia serta kendala dalam kerjasama tersebut. Tulisan ini menjelaskan motivasi kedua negara melakukan kerjasama serta lebih deskriptif dalam menjelaskan kendala yang dihadapi Indonesia dan Malaysia dalam melakukan kerjasama terkait isu ketenagakerjaan. Handayani menjelaskan adanya kepentingan nasional kedua negara dalam melakukan hubungan bilateral. Hal ini menunjukkan bahwa Handayani secara implisit menggunakan pendekatan realisme dalam menjelaskan latar belakang kerjasama Indonesia dan Malaysia. Selain itu, terdapat tulisan Yovinus (2016) menjelaskan adanya mutual benefit atau keuntungan bersama untuk Indonesia dan Malaysia. Menggunakan pendekatan liberalisme, ia menjelaskan bahwa dengan adanya keuntungan bersama dapat mendorong hubungan baik antara Indonesia dan Malaysia dan dapat meningkatkan kesejahteraan Indonesia.

Selain menggunakan pendekatan realisme dan liberalisme, penelitian lainnya yaitu Insani (2015), Meilinda (2017), dan Hidayat (2017) menggunakan pendekatan lain dalam menjelaskan kerjasama terkait ketenagakerjaan. Insani (2015) menggunakan konsep diplomasi dalam mendeskripsikan upaya Indonesia membebaskan TKI dari hukuman mati. Sedangkan, Meilinda (2017) melihat adanya pengaruh aktor domestik dalam hubungan Indonesia-Malaysia melalui pendekatan kebijakan luar negeri. Di sisi lain, Hidayat (2017) menggunakan pendekatan HAM dalam menjelaskan perlindungan hak TKI di Malaysia. Tulisan lain misalnya Christie (2016) menyoroti kendala kerjasama Indonesia-Malaysia dan NGO dalam isu tenaga kerja. Christie (2016) berpendapat bahwa kendala NGO Humana di bidang pendidikan adalah tidak seimbangnya jumlah guru dengan murid untuk menyediakan pendidikan anak TKI di Sabah Malaysia.

Tulisan-tulisan di atas hanya menjelaskan hubungan antara dua negara, yaitu Indonesia dan Malaysia dalam menangani isu tenaga kerja dan pendidikan. Tulisan-tulisan di atas belum secara detail membahas peran NGO dalam kerjasama antara Indonesia dan Malaysia. Terdapat tulisan yang menjelaskan tentang peran NGO dalam menangani suatu isu. Humphreys (1996) menjelaskan tentang peran NGO dalam bidang lingkungan dengan memberi kasus konservasi hutan. Melalui studi kasus konservasi hutan, tulisan Humphreys (1996) menunjukkan tiga hasil utama. Pertama, NGO dapat menyebabkan perubahan perilaku suatu negara dalam sistem internasional. NGO telah menjadi pusat perubahan hubungan negara dengan masyarakat yang berperan penting dalam rezim 
lingkungan. Kedua, NGO memiliki tugas untuk menyusun pedoman dalam pembentukan norma dan prinsip dalam rezim internasional. NGO dapat membentuk koalisi dan melakukan negosiasi dengan pemerintah. Ketiga, para ahli teori rezim perlu mempertimbangkan peran non-pemerintah.

Selanjutnya, terdapat tulisan lain yang membahas tentang peran NGO di bidang pembangunan (Lewis, 1997). Tulisan Kwiatkowski (2005) menjelaskan tentang peran NGO di bidang kesehatan di Filipina. NGO ini masuk ke wilayah Ifugao yang memiliki identitas dan budaya daerah yang kuat untuk memperkenalkan biomedicine. Tulisan Thomas et al (2010) menjelaskan tentang hubungan NGO lokal dengan negara di Kerala, India. NGO ini menunjukkan multi identitas sebagai proses dalam menjalin hubungan baik dengan negara. NGO di Kerala melakukan kolaborasi, mengisi kerenggangan, dan menawarkan alternatif pemecahan masalah terhadap negara. Kunci dalam hubungan NGO dengan negara di Kerala, India ini adalah persamaan identitas agar kedua pihak dapat menjalin hubungan baik. Selanjutnya, tulisan Batley dan Rose (2010) menjelaskan tentang kolaborasi antara NGO dengan pemerintah dalam memberikan pendidikan di negara-negara Asia Selatan, yaitu Bangladesh, India, dan Pakistan. Kolaborasi antara NGO dan pemerintah ini dapat berhasil dengan dua cara; tidak bergantung pada sumber terbatas untuk membiayainya dan membangun hubungan informal dengan pemerintah. Hal tersebut tidak hanya memperkuat hubungan antar NGO, melainkan dapat memperkuat hubungan dengan pihak internal lain.

Hasil-hasil penelitian tersebut menunjukkan bahwa telah ada tulisan yang membahas NGO dengan pemerintah dalam suatu isu, khususnya isu pendidikan. Namun, belum terdapat tulisan yang secara detail membahas alasan NGO dalam menangani isu pendidikan untuk anak-anak yang termarjinalkan. Oleh karena itu, penelitian ini akan menjelaskan alasan suatu NGO dalam memberikan pendidikan untuk anak-anak marjinal, dalam hal ini penulis mengambil studi kasus anak-anak TKI termasuk TKI ilegal. Lebih lanjut, penelitian ini akan melihat hubungan NGO dengan pemerintah negara Indonesia di bidang pendidikan. Hal ini penting untuk dibahas karena isu pekerja ilegal adalah isu sensitif. Di samping itu, pendidikan ini merupakan isu yang penting, termasuk bagi anak-anak TKI di negara lain.

Berbeda dengan penelitian-penelitian terdahulu, artikel ini menggunakan kerangka pemikiran NGO sebagai Transnational Advocacy Network (TAN). NGO merupakan jaringan dengan prinsip ide dan nilai yang memotivasi untuk membuat suatu aksi. Ide ini yang kemudian menjadi landasan NGO mengambil peran dalam suatu isu. Ide juga mempengaruhi NGO menentukan tujuan dan target, sehingga dapat berperan dalam suatu isu. Penjelasan dalam artikel ini diawali dengan tulisan terdahulu yang 
telah membahas isu pendidikan, baik yang melibatkan negara maupun NGO. Kemudian akan dijelaskan kerangka pemikiran dalam artikel ini. Selanjutnya, profil NGO Humana akan dijelaskan diikuti dengan analisis ide yang membentuk NGO Humana serta tujuan, target, dan peran NGO Humana.

\section{NGO sebagai Transnational Advocacy Network}

Isu dalam hubungan internasional mengalami perkembangan, begitu pula dengan aktor-aktor yang terlibat. Aktor dalam hubungan internasional tidak hanya terbatas pada negara, namun aktor non-negara juga mulai memiliki peran dalam hubungan internasional. Pada pertengahan abad ke20 terjadi perkembangan Non-Governmental Organizations (NGOs) dalam hubungan internasional (Ohanyan, 2009). NGO ini mulai menjalin hubungan dengan International Governmental Organizations (IGOs) maupun dengan negara lain secara bilateral dan multilateral. Hal ini menunjukkan bahwa hubungan internasional mengalami perkembangan dilihat dari aktor yang terlibat di dalamnya. Perkembangan NGO ini kemudian mendorong para ahli untuk membahas tentang NGO dalam hubungan internasional. Para ahli menyebutkan bahwa pertumbuhan NGO ini mendorong kemunculan "world society" dan masuk dalam era "politics beyond the state" (Johnson \& Prakash, 2007). Hal ini kemudian mendorong pembahasan tentang NGO dalam berbagai sudut pandang. NGO juga dianggap sebagai gerakan individu secara kolektif untuk mengejar tujuan politik, ekonomi, dan sosial. Pada akhirnya, kelompok ini lebih memilih mencapai tujuannya melalui NGO dibandingkan melalui bentuk kerjasama kolektif yang lain, seperti unilateral.

Para ahli sepakat bahwa NGO merupakan institusi yang terdiri dari individu-individu dengan tujuan sama (pursue shared goals). Lebih lanjut, para ahli memiliki pandangan yang berbeda dalam menjelaskan peran NGO secara rinci. Para ahli masing-masing menjelaskan melalui sudut pandang politik, sosiologi, dan non-profit sebagai alat analisisnya. Ahli politik menjelaskan NGO dengan perannya yang bukan merupakan pemerintah dan bagaimana NGO memberikan pengaruh terhadap kebijakan publik dan kebijakan bisnis. Dari perspektif sosiologi politik, NGO dapat memengaruhi kebijakan publik maupun kebijakan bisnis. Namun, para ahli ini tidak melihat kesamaan tujuan antara NGO dengan pemerintah maupun perusahaan. Ahli NGO dalam bidang ini juga belum secara sistematis menjelaskan asal NGO (mengapa, dimana, dan kapan NGO dibentuk), internal governance (agen dan akuntabilitas), dan strategi organisasi (target dan mobilisasi) (Johnson \& Prakash, 2007).

Perdebatan selanjutnya muncul dari ahli yang memandang NGO sebagai lembaga non-profit. Ahli ini menjelaskan bahwa untuk mempelajari NGO secara sistematis, diperlukan pemahaman tentang asal, struktur, dan strategi sebagai atribut utama yang dimiliki NGO. Pendekatan yang 
digunakan oleh ahli ini adalah pendekatan kolektif atau collective action. NGO dipandang memiliki persamaan dengan perusahaan, aktor non-pemerintah yang lain. Individu-individu melalui NGO mengejar tujuan yang sama atau dapat disebut dengan common goal (Johnson \& Prakash, 2007). Keck dan Sikkink merupakan ahli yang menjelaskan NGO sebagai non-profit. Keck dan Sikkink menyebut NGO sebagai Transnational Advocacy Network (TAN) yang memiliki pengaruh dalam politik internasional. Keck dan Sikkink (1998) menjelaskan bahwa interaksi antara aktor non-negara dan negara lain dan organisasi internasional merupakan jaringan transnasional dalam politik internasional. Beberapa merupakan aktor ekonomi dan perusahaan. Jaringan ini diikat oleh shared ideas yang kemudian mendorong dalam memengaruhi suatu kebijakan. Jaringan dengan prinsip ide dan nilai ini yang memotivasi untuk membuat suatu aksi.

Advocacy networks dapat beroperasi di level domestik maupun transnasional. Dengan membangun hubungan antara masyarakat, negara, dan organisasi internasional, advocacy networks ini memiliki akses dalam sistem internasional. Dalam beberapa bidang seperti lingkungan dan hak asasi manusia, advocacy networks juga mendorong ketersediaan sumber internasional ke dalam domestik suatu negara. Isu-isu yang dipromosikan oleh advocacy networks ini seperti isu hak asasi manusia, lingkungan, dan hak-hak perempuan. Meski memiliki berbagai isu, advocacy networks ini memiliki persamaan yaitu menghargai ide dan nilai dasar, mempercayai bahwa setiap individu memiliki perbedaan, dan menghargai kreativitas penggunaan informasi (Keck \& Sikkink, 1998). Transnational Advocacy Networks dimotivasi oleh nilai daripada material. Oleh karena itu, Transnational Advocacy Networks ini selalu membawa ide, nilai, dan norma dalam perilakunya. Norma ekspektasi kolektif dari perilaku aktor dengan identitas yang dimilikinya. Norma mendefinisikan identitas dari seorang aktor, yang pada gilirannya dapat memengaruhi aksi yang dilakukan. Hal ini menunjukkan bahwa adanya suatu norma dapat memengaruhi perilaku aktor dalam politik internasional.

NGO internasional maupun domestik memiliki peran penting. NGO dapat memiliki koneksi dengan berbagai pemangku kepentingan seperti negara, organisasi internasional, dan masyarakat (Keck \& Sikkink, 1998). NGO ini juga memiliki common goal dan common target. Dengan hal-hal tersebut dapat dikatakan bahwa NGO merupakan transnational advocacy network yang dapat melakukan penyebaran ide dan norma dalam sistem internasional. Secara garis besar, NGO berperilaku berdasarkan ide dasar yang dapat berupa nilai atau norma yang mendorong adanya tujuan. Gambar 2 di bawah ini menunjukkan secara singkat alur analisis dalam tulisan ini. Perilaku NGO didasarkan pada ide yang dapat berupa nilai dan norma yang kemudian mendorong adanya tujuan yang akan dicapai. Pada akhirnya dapat terbentuk NGO untuk menangani suatu isu. 


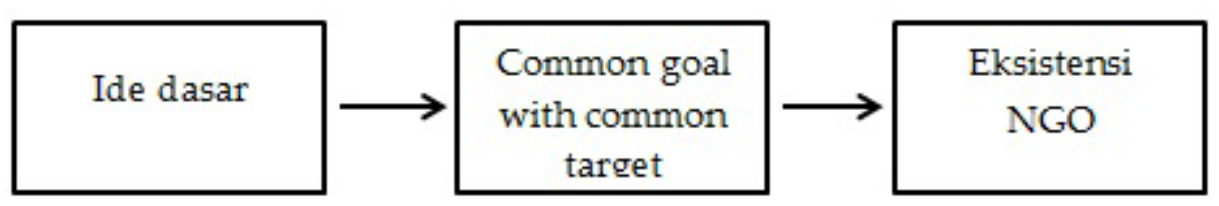

Gambar 2 Alur berpikir tulisan ini

\section{Profil NGO Humana Child Aid Society}

Humana Child Aid Society merupakan suatu NGO atau LSM di Malaysia yang mulai dirintis tahun 1991. Humana memberikan pendidikan kepada anak-anak yang tidak memiliki akses untuk bersekolah. Sampai saat ini, Humana memberikan pendidikan bagi 12.000 anak di perkebunan Sabah dan tempat terpencil lainnya. Pada awal dirintis, Humana didukung oleh Corporate Foundation, namun sekarang dukungan utama Humana berasal dari perusahaan perkebunan di Malaysia (Humana, 2015). Humana memiliki tujuan untuk mempromosikan, menyediakan, dan mengoperasikan pusat-pusat pembelajaran di Sabah, terutama untuk anak-anak yang tinggal di perkebunan dan anak-anak tidak berdokumen dari negara lain. Humana bekerjasama dengan perkebunan-perkebunan di Sabah untuk memberikan pendidikan bagi anak-anak atas izin dari Kementerian Pendidikan Malaysia.

Humana memiliki empat misi dalam menjalankan tugasnya. Misi pertama adalah untuk mengurangi pekerja anak di sektor perkebunan, sehingga pada akhirnya tidak ada pekerja anak. Misi kedua, dengan adanya Humana dapat menyediakan pendidikan holistik bagi anak-anak dari TK hingga kelas 6 Sekolah Dasar. Hal ini menunjukkan bahwa hak atas pendidikan dapat terpenuhi. Misi ketiga adalah pengembangan lebih lanjut melalui program pendidikan termasuk olahraga dan seni. Misi keempat, dengan adanya Humana ini dapat mendukung pembangunan berkelanjutan yang dicanangkan oleh PBB sehingga dapat berkontribusi bagi pembangunan berkelanjutan di Malaysia dalam bidang pendidikan (Humana, 2015).

Humana sebagian besar didanai oleh kontribusi bulanan yang diterima oleh perkebunan kelapa sawit. Oleh karena itu, Humana secara tidak langsung mempromosikan perkembangan perkebunan minyak sawit secara berkelanjutan dengan menyediakan pusat pendidikan di Sabah. Hal ini dapat membantu mengurangi pergantian pekerja di perkebunan karena pekerja memiliki kepercayaan terhadap pendidikan anak-anak mereka. Dengan tenaga kerja yang stabil dapat menghasilkan produktivitas yang lebih tinggi untuk perkebunan (RSPO, 2008). Pada akhirnya, perkebunan memiliki keuntungan dengan adanya Humana ini. 
Humana memiliki program dalam memberikan pendidikan bagi anak-anak di Sabah. Guru di Humana menggunakan alat dan metode yang berpusat pada anak seperti lagu, alat bantu visual, dan latihan kelompok untuk mempromosikan pembelajaran partisipatif. Siswa juga diberi peningkatan kesadaran akan sumber daya tabungan dengan menyimpan sejumlah uang dalam kotak tabungan. Sebagian besar siswa Humana ini berasal dari sektor tanpa kewarganegaraan dan terpinggirkan atau anakanak pekerja perkebunan. Sedangkan, beberapa guru juga mewakili kelompok yang terpinggirkan dan pekerja migran (Aflatoun International, 2018).

Humana sebagai NGO memiliki ide dasar dalam berperan memberikan fasilitas pendidikan terhadap anak-anak, terutama anak-anak TKI di Sabah. Ide yang dipegang oleh Humana adalah "education for all," yaitu pendidikan untuk semua. Sebelum ide ini muncul, terdapat ide dasar yang melatarbelakangi ide "education for all" ini. Ide dasar yang terlebih dahulu ada adalah yang tercantum dalam The Universal Declaration of Human Rights 1948 dan Convention on the Rights of the Child. Ide yang memberikan hak pendidikan untuk semua anak, termasuk anak-anak TKI ini tidak muncul dengan sendirinya. Ide ini muncul juga berdasarkan sejarah kondisi pendidikan anak-anak buruh migran di wilayah Sabah, Malaysia. Oleh karena itu, kemunculan ide "education for all" ini tidak terlepas dari sejarah migran di Malaysia. Isu migran ini yang kemudian memberikan proses kemunculan ide bahwa pendidikan merupakan hak semua orang, termasuk anak-anak migran di Malaysia.

Di Malaysia, terdapat empat kelompok yang dimasukkan dalam orang-orang stateless atau tidak memiliki kewarganegaraan. Kelompok ini adalah pengungsi Rohingya dari Myanmar, orang Malaysia keturunan India, anggota komunitas Bajau Laut, serta anak-anak pengungsi dan migran di Sabah (Allerton, 2014). Hal ini menunjukkan bahwa anak-anak migran di Sabah termasuk dalam populasi stateless di Malaysia. Keberadaan migran di Sabah mulai meningkat pada tahun 1970an sampai 1980an. Pengungsi dari Filipina Selatan mulai berdatangan di Sabah, begitu pula dengan pekerja dari Indonesia yang berdatangan ke Sabah. Migran dari Indonesia yang bekerja di perkebunan sawit mulai meningkat (Allerton, 2014). Migran ini membawa anak-anaknya meski tanpa dokumen resmi. Hal ini yang kemudian membuat meningkatkan anak-anak tanpa kewarganegaraan di daerah Sabah Malaysia.

Banyaknya pekerja migran ini mendorong adanya kebijakan imigrasi pemerintah Malaysia. Kebijakan yang dibuat oleh pemerintah Malaysia ini menyebutkan bahwa pekerja migran hanya boleh tinggal di Malaysia selama lima tahun. Selain itu, pekerja migran tidak boleh membawa keluarganya ke Malaysia atau menikah dan memiliki anak ketika berada di Malaysia (Allerton, 2014). Hal ini dikarenakan status migran yang mereka miliki, 
jika memiliki anak ketika berada di Malaysia maka anak-anaknya tersebut tidak memiliki kewarganegaraan.

Kenyataannya, banyak pekerja migran Indonesia yang kemudian menikah dan memiliki anak di Malaysia. Hal ini yang kemudian membuat status pekerja migran yang legal menjadi bermasalah. Pekerja migran yang melahirkan anak di Malaysia ini membuat anak-anaknya tidak memiliki status kewarganegaraan. Begitu pula dengan migran yang menikah di Malaysia, mereka tidak memiliki dokumen pernikahan yang resmi. Anakanak yang lahir dari pekerja migran Indonesia selama di Malaysia ini kemudian kesulitan mendapatkan hak-haknya karena status ilegal. Hal ini menunjukkan status ilegal didapat dengan beberapa cara. Pekerja migran yang tidak memiliki dokumen resmi bersama keluarganya dapat disebut sebagai pekerja ilegal. Hal ini juga berdampak pada status anak-anaknya yang ilegal. Selain itu, pekerja migran yang memiliki dokumen dan termasuk pekerja legal, namun menikah dan melahirkan anak di Malaysia, maka anak-anaknya tidak mendapatkan status kewarganegaraan. Dengan kata lain, anak-anak yang lahir di Malaysia dari pekerja migran secara otomatis tidak memiliki dokumen resmi dan dikatakan sebagai ilegal. Hal ini yang kemudian menyebabkan keterbatasan anak-anak TKI dalam mendapatkan hak-haknya.

Pada awalnya, kondisi TKI yang ilegal memiliki pengaruh terhadap anak-anaknya yang tidak mendapatkan hak pendidikan di negara Malaysia. Anak-anak TKI yang ilegal ini tidak memiliki dokumen yang menyebabkan kehilangan hak mendapatkan pelayanan pendidikan dan kesehatan. Tanpa adanya surat-surat yang membuktikan kewarganegaraan, pemerintah Malaysia tidak mengakui anak-anak TKI ilegal secara resmi. Sehingga, mereka juga tidak mendapatkan layanan kesehatan dan pendidikan. Saat Malaysia memperoleh kemerdekaannya pada tahun 1957, semua anak dapat bersekolah dari manapun mereka berasal dan dokumen apapun yang mereka miliki. Namun, seiring berjalannya waktu, populasi migran terhitung hampir sepertiga dari 3,2 juta orang Sabah yang kemudian membuat praktik pelayanan pendidikan itu memiliki kendala. Pemerintah Malaysia pada akhirnya tidak bersedia memberikan alokasi dana untuk memberikan pendidikan secara universal (Motlagh, 2013). Hal ini juga yang mendorong anak-anak migran kesulitan dalam memperoleh pendidikan di Malaysia, khususnya di wilayah Sabah. Tidak adanya dana dari pemerintah Malaysia yang menjadi kendala dalam memberikan pendidikan anak-anak migran di Sabah mendorong adanya donor dari organisasi internasional. Torben Venning yang merupakan kewarganegaraan Denmark melakukan kampanye pendidikan di perkebunan untuk wilayah Sabah. Venning membuka fasilitas pendidikan pada tahun 1990 untuk mendidik 70 anakanak petani (Motlagh, 2013). Organisasi yang dibentuk Venning ini adalah Humana Child Aid Society. 


\section{Peran NGO Humana dalam Mewujudkan Gagasan "Education for All"}

Pada dasarnya, anak-anak TKI memiliki hak untuk mendapatkan pendidikan. Hak-hak untuk memperoleh pendidikan termasuk yang disebutkan dalam Universal Declaration of Human Rights. Deklarasi ini menghasilkan dokumen yang memberikan definisi secara detail tentang hak-hak dan kebebasan yang dimiliki oleh setiap manusia secara setara dan tidak dapat dipisahkan. Pasal 26 Universal Declaration of Human Rights menjelaskan sebagai berikut:

(1) Everyone has the right to education. Education shall be free, at least in the elementary and fundamental stages. Elementary education shall be compulsory. Technical and professional education shall be made generally available and higher education shall be equally accessible to all on the basis of merit. (2) Education shall be directed to the full development of the human personality and to the strengthening of respect for human rights and fundamental freedoms. It shall promote understanding, tolerance and friendship among all nations, racial or religious groups, and shall further the activities of the United Nations for the maintenance of peace. (3) Parents have a prior right to choose the kind of education that shall be given to their children

Pasal 26 tersebut menunjukkan bahwa pendidikan merupakan hak setiap manusia. Pendidikan dasar merupakan hal wajib dan dapat diakses oleh semua orang. Pendidikan harus diarahkan untuk semua manusia karena hal ini merupakan hak asasi manusia dan kebebasan mendasar. Pemahaman tentang hak memperoleh pendidikan dasar ini harus ditekankan pada semua bangsa, kelompok ras, dan agama. Selain itu, orang tua juga memiliki hak untuk memilih jenis pendidikan yang diberikan kepada anaknya. Pasal 26 ini menunjukkan ide dasar bahwa pendidikan merupakan hak asasi manusia dan harus dapat dipenuhi sebagai kebebasan mendasar.

Selain Universal Declaration of Human Rights sebagai dasar, Convention on the Rights of the Child menjelaskan secara khusus hak memperoleh pendidikan bagi anak-anak. Konvensi ini memiliki isi tentang hak-hak yang harus diperoleh anak-anak. Pada Pasal 28 dan 29 dijelaskan tentang hak anak untuk memperoleh pendidikan. Pasal 28 dan 29 Convention on the Rights of the Child berbunyi sebagai berikut:

Article 28: (Right to education): All children have the right to a primary education, which should be free. Wealthy countries should help poorer countries achieve this right. Discipline in schools should respect children's dignity. For children to benefit from education, schools must be run in an orderly way - without the use of violence. Any form of school discipline should take into account the child's human dignity. Therefore, 
governments must ensure that school administrators review their discipline policies and eliminate any discipline practices involving physical or mental violence, abuse or neglect. The Convention places a high value on education. Young people should be encouraged to reach the highest level of education of which they are capable.

Article 29 (Goals of education): Children's education should develop each child's personality, talents and abilities to the fullest. It should encourage children to respect others, human rights and their own and other cultures. It should also help them learn to live peacefully, protect the environment and respect other people. Children have a particular responsibility to respect the rights their parents, and education should aim to develop respect for the values and culture of their parents. The Convention does not address such issues as school uniforms, dress codes, the singing of the national anthem or prayer in schools. It is up to governments and school officials in each country to determine whether, in the context of their society and existing laws, such matters infringe upon other rights protected by the Convention.

Pada Pasal 28 di atas menjelaskan bahwa semua anak memiliki hak atas pendidikan dasar yang gratis. Bahkan, negara kaya harus membantu negara miskin untuk memenuhi hak anak ini. Setiap anak harus mendapatkan manfaat dari pendidikan tanpa menggunakan kekerasan. Hal ini dikarenakan setiap perilaku harus memperhatikan martabat anakanak. Dalam hal ini, pemerintah juga harus berperan dalam memastikan pendidikan yang diberikan kepada anak dapat berjalan dengan baik tanpa adanya kekerasan fisik atau mental, pelecehan, atau pengabaian. Hal ini menunjukkan bahwa pendidikan anak sangat dilindungi. Selanjutnya, pada Pasal 29 di atas menjelaskan tentang tujuan dari pendidikan anak. Pendidikan kepada anak harus dapat mengembangkan kepribadian, bakat, dan kemampuan anak secara maksimal. Pendidikan juga harus bertujuan untuk mengembangkan rasa hormat terhadap nilai-nilai dan budaya serta menghormati hak asasi manusia. Dengan adanya pasal ini, menunjukkan bahwa pendidikan anak harus dapat mencapai tujuan tertentu yang pastinya untuk mendorong tumbuh-kembang anak secara maksimal.

Dari Universal Declaration of Human Rights dan Convention on the Rights of the Child tersebut muncul ide dasar bahwa pendidikan adalah untuk semua anak. Inilah akar dari gagasan "education for all." Pemerintah Indonesia dan Malaysia sepakat tentang ide "education for all" ini. Hal ini terdapat pada Malaysia's UN SDGs on education bahwa pendidikan adalah untuk semua anak. "Education for all" ini bertujuan untuk memastikan semua anak menyelesaikan pendidikan dasar sehingga anak dapat memiliki ilmu pengetahuan dan berpartisipasi aktif dalam masyarakat (Humana, 2015). 
Selain pemerintah Malaysia, pemerintah Indonesia juga setuju dengan "education for all." Hal ini disampaikan oleh Duta Besar LBBP RI untuk Malaysia bahwa "education for all" adalah hak asasi manusia.

Selain negara, ide "education for all" ini juga diterima oleh NGO, termasuk Humana yang memiliki peran dalam memberikan pendidikan anak-anak TKIdiSabah. Humana memberikan kontribusi dalam pemenuhan "education for all" bagi anak-anak. Hal ini sejalan dengan visi Humana untuk memberikan pendidikan bagi anak-anak yang termarjinalkan di daerah Sabah (Humana, 2015). Humana juga berperan berdasarkan Convention on the Rights of the Child bahwa semua anak memiliki hak mendapatkan pendidikan termasuk anak-anak termarjinalkan. Hal ini yang mendorong Humana berperan aktif dalam memberikan pendidikan terhadap anakanak, khususnya anak-anak TKI di Sabah, Malaysia.

Dari pemaparan di atas, ide "education for all" ini muncul berdasarkan kondisi migran di Malaysia yang kehilangan hak-haknya. Selanjutnya, dengan berlandaskan Universal Declaration of Human Rights dan Convention on the Rights of the Child, muncul ide "education for all" yang memberikan hak pendidikan kepada semua anak termasuk anak-anak TKI di Sabah. Pihak yang terlibat dalam memberikan pendidikan anak-anak TKI di Sabah, seperti Malaysia, Indonesia, dan NGO Humana, sepakat dengan ide "education for all" ini. Hal tersebut yang kemudian mendorong mereka memberikan pendidikan terhadap anak-anak TKI di Sabah. Begitu pula dengan NGO Humana yang kemudian menyusun agenda tujuan dan target dalam memberikan pendidikan untuk anak-anak TKI di Sabah.

Humana memiliki tujuan dan target yang juga berdasarkan ide dasar dari Humana dalam memberikan pendidikan terhadap anak-anak. Dengan ide "education for all" yang telah dijelaskan sebelumnya, Humana memiliki tujuan dan target secara umum. Tujuan dan target secara umum yang dimaksud di sini adalah Humana tidak memandang suku, bangsa, dan ras dalam memberikan fasilitas pendidikan terhadap anak-anak. Hal ini berdasarkan ide bahwa pendidikan adalah hak asasi semua manusia, termasuk semua anak-anak. Humana memberikan pelayanan pendidikan kepada anak-anak yang tidak memiliki akses terhadap pendidikan akibat dari jarak, ketersediaan pendidikan, dan status legal ataupun ilegal. Humana memberikan pendidikan kepada anak-anak termarjinalkan tersebut mulai dari Taman Kanak-Kanak sampai kelas 6 Sekolah Dasar dengan menggunakan kurikulum Malaysia (Humana, 2015). Humana memiliki komitmen agar semua anak-anak mendapatkan pendidikan yang layak meskipun dalam kondisi yang terbatas.

Selain itu, Humana juga mengembangkan program pendidikan dalam bidang olahraga dan seni. Humana juga melibatkan guru-guru yang berasal dari Indonesia untuk bekerjasama dalam memberikan pelayanan 
pendidikan melalui Community Learning Centre (CLC) dari pemerintah Indonesia (Humana, 2015). Hal ini menunjukkan bahwa Humana memiliki keseriusan untuk memberikan fasilitas pendidikan bagi anak-anak yang termarjinalkan. Dalam hal ini, Humana memiliki sasaran anak-anak TKI karena dilihat dari banyaknya TKI di Sabah yang anak-anaknya tidak mendapatkan pendidikan layak.

Tujuan utama dari Humana adalah memberikan fasilitas pendidikan kepada ribuan anak-anak termarjinalkan di Sabah. Hal ini berdasarkan Convention on the Rights of the Child. Anak-anak termarjinalkan di Sabah ini didominasi oleh anak-anak tenaga kerja yang berasal dari Indonesia. Sehingga, anak-anak TKI ini tidak luput dari sasaran Humana dalam memberikan fasilitas pendidikan. Hal ini menunjukkan bahwa dengan ide "education for all" ini, Humana memiliki tujuan dan target yang jelas untuk memberikan pendidikan. Targetnya tidak berdasarkan suku, bangsa, maupun ras, namun semua anak-anak memiliki hak untuk mendapatkan pendidikan yang difasilitasi oleh Humana. Humana menjalin kerjasama dengan pemerintah Indonesia untuk memberikan pelayanan pendidikan anak-anak TKI di Sabah. Pada awalnya, kerjasama ini dimulai dengan dialog-dialog antara negara Malaysia, Indonesia, dan NGO pendidikan yang ada di Malaysia. Pertemuan-pertemuan tersebut yang kemudian mendorong adanya kerjasama antara aktor non negara dan aktor negara dalam memberikan pelayanan pendidikan anak-anak di Sabah, Malaysia. Dalam hal ini adalah Humana bekerjasama dengan pemerintah Indonesia dan Malaysia dalam memberikan pendidikan terhadap anak-anak TKI di Sabah.

Pemberian pelayanan pendidikan bagi anak-anak TKI tidak muncul dengan sendirinya, namun memiliki dinamika. Sebelum tahun 2002, TKI yang ilegal masih bisa dengan bebas memasukkan anaknya pada sekolah yang ada di Malaysia. Namun setelah terdapat beberapa aturan baru, kebijakan tersebut mengharuskan setiap pekerja asing memiliki dokumen lengkap untuk dapat diterima baik itu sekolah negeri maupun sekolah swasta. Permasalahan ini pada akhirnya mempersulit pelajar warga negara Indonesia yang kebanyakan orangtuanya tidak memiliki dokumen lengkap. Selain itu, para orang tua yang bekerja ini kurang menyadari arti penting dan manfaat pendidikan. Permasalahan ini pada akhirnya mendorong Indonesia untuk berusaha memberikan pendidikan layak bagi anak-anak TKI Indonesia yang berada di wilayah Sabah. Selain itu, Indonesia juga melakukan diplomasi kepada pihak Malaysia untuk mencari solusi agar anak-anak TKI ini tetap bisa mendapatkan pendidikan tanpa harus masuk ke dalam sekolah formal Malaysia.

Pada Annual Consultation tahun 2006, terjadi kesepakatan antara Presiden Indonesia Susilo Bambang Yudhoyono dengan Perdana Menteri 
Malaysia Abdulah Ahmad Badawi.yang menyepakati pendirian Sekolah Indonesia Kota Kinabalu (SIKK) yang tertuang dalam pernyataan bersama (joint statement) kedua negara. Dalam pernyataan bersama (joint statement) diantara kedua pemimpin tersebut disepakati juga mengenai pendirian Sekolah Indonesia Kota Kinabalu (SIKK) yang banyak menampung anakanak yang tinggal di wilayah Kota Kinabalu. SIKK ini menjadi sekolah induk bagi Community Learning Center (CLC) yang tersebar di wilayah Sabah dengan jumlah mencapai 53.000 anak usia sekolah. Sementara untuk anak-anak TKI usia TK dan SD dibantu oleh Humana dengan jumlah sekitar 12.000 anak (KBRI Kuala Lumpur, 2018). Kesepakatan antara Indonesia dan Malaysia ini membuat anak-anak Indonesia bisa mendapatkan pendidikan yang layak tanpa harus takut dengan ketidaklengkapan dokumen yang dimiliki orang tuanya. Pertemuan tersebut merupakan kelanjutan dari Annual Consultations 2004 antara Presiden Megawati dengan Perdana Menteri Abdullah Ahmad Badawi yang menyepakati bahwa Indonesia dapat mengirimkan guru-guru untuk membantu pendidikan anak-anak TKI di wilayah Sabah.

Sejak tahun 2006 ini, pemerintah Indonesia secara aktif memberikan bantuan tenaga pendidik ke Humana. Pemerintah Indonesia melalui Departemen Pendidikan Nasional di tahun 2006 mengirimkan 109 tenaga pendidik untuk diperbantukan mendidik peserta didik di Humana. Selanjutnya, pemerintah Indonesia secara bertahap mengirim guru melalui beberapa fase, yaitu Fase I tahun 2006-2008, Fase II tahun 2009-2011, dan Fase III tahun 2011-2017 (KBRI Kuala Lumpur, 2018). Pada Fase I tahun 2006 ini 109 pendidik bukan Pegawai Negeri Sipil ditugaskan di Sabah selama dua tahun, termasuk diperbantukan di Humana. Pendidikan fase ini berhasil mengirimkan 60 anak TKI dari Humana untuk melanjutkan pendidikan pada sekolah formal di Indonesia. Selanjutnya, pendidik Fase I digantikan oleh pendidik Fase II sebanyak 84 orang pada tahun 2009. Kebijakan Menteri Pendidikan Nasional ini mengharuskan pendidik untuk memberikan pelayanan pendidikan anak-anak TKI di Sabah, termasuk anak-anak TKI yang telah bersekolah di Humana. Kemudian, pendidik Fase III dikirimkan pada tahun 2009. Pada fase ini, Kemendikbud kembali mengirim 585 orang guru PNS dan bukan PNS yang dilakukan dalam 8 tahap pengiriman hingga tahun 2017 (KBRI Kuala Lumpur, 2018). Guruguru ini juga ikut diperbantukan ke Humana untuk dapat memberikan pelayanan pendidikan ke anak-anak TKI di Sabah.

Pengiriman guru dari Indonesia untuk diperbantukan ke Humana menunjukkan bahwa terdapat kerjasama antara aktor negara dan non negara dalam memberikan pendidikan anak-anak TKI di Sabah. Setelah terjadi kesepakatan antara pemerintah Indonesia dan Malaysia, pemerintah Indonesia dapat mengirimkan tenaga pendidik ke Malaysia, 
termasuk bergabung bersama Humana sebagai NGO yang telah lebih dahulu memberikan pelayanan pendidikan di wilayah Sabah. Hal ini menunjukkan bahwa Humana dan pemerintah Indonesia memiliki peran dalam memberikan pendidikan anak-anak TKI di Sabah dengan ide dasar "education for all." Tanpa memandang suku, bangsa, dan ras, aktor negara dan non negara ini dapat bersama-sama memberikan pelayanan pendidikan terhadap anak-anak yang termarjinalkan di wilayah Sabah, Malaysia.

\section{Kesimpulan}

Artikel ini menunjukkan bahwa terdapat alasan yang melatarbelakangi NGO dalam ikut serta menangani suatu isu pendidikan. Dalam hal ini, Humana sebagai NGO di bidang pendidikan memiliki ide sebagai dasar perilaku dalam memberikan pelayanan pendidikan terhadap anak-anak yang termarjinalkan. Ide dasar "education for all" ini mendorong Humana melakukan upaya untuk memberikan pelayanan pendidikan anak-anak TKI di Sabah tanpa memandang suku, bangsa, dan ras. Humana memandang bahwa hakikatnya pendidikan adalah hak asasi manusia yang harus dilindungi dan diimplementasikan. Dengan ide dasar "education for all," Humana memiliki target untuk memberikan pendidikan kepada semua anak-anak, termasuk anak-anak TKI di Sabah.

Selain itu, isu pendidikan anak-anak TKI di Sabah ini menunjukkan bahwa aktor negara dan non negara dapat melakukan kerjasama dalam memberikan fasilitas pendidikan. Kesepakatan antara pemerintah Indonesia dan pemerintah Malaysia mendorong pemerintah Indonesia dapat mengirimkan tenaga pendidik ke Malaysia. Lebih lanjut, pemerintah Indonesia bekerjasama dengan NGO Humana memberikan fasilitas pendidikan terhadap anak-anak TKI di Sabah secara berkelanjutan. Hal ini menunjukkan bahwa baik aktor negara maupun aktor non negara memiliki pandangan yang sama tentang "education for all."

Namun, terdapat kendala tentang pendidikan yang diberikan oleh Humana kepada anak-anak TKI di Sabah. Kurikulum yang diajarkan merupakan kurikulum Malaysia dengan buku ajar juga sesuai dengan materi Malaysia. Hal ini perlu mendapat perhatian oleh pemerintah Indonesia, agar anak-anak TKI ini mendapatkan kurikulum yang sesuai dan dapat melanjutkan kuliah formal di Indonesia. Perbantuan guru dari pemerintah Indonesia ke Sabah, termasuk ke Humana, diharapkan dapat menyelaraskan kurikulum yang dibutuhkan untuk anak-anak TKI di Sabah. Lebih lanjut, kerjasama antara pemerintah Indonesia dan Humana seharusnya berkelanjutan agar dapat memberikan pelayanan pendidikan terhadap anak-anak TKI di Sabah secara maksimal. 


\section{Daftar Pustaka}

Aflatoun International (2018) Humana Child Aid Society Sabah [Online]. Aflatoun International. Tersedia dalam: <https://www.aflatoun. org/projects/humana-child-aid-society-sabah/> [Diakses 8 Mei 2019].

Allerton, C. (2014). Statelessness and the Lives of the Children of Migrants in Sabah, East Malaysia. Journal of International and European Law, 19(1-2), pp. 26-34.

Batley, R. \& Rose, P. (2010). Collaboration in Delivering Education: Relations between Governments and NGOs in South Asia. Development in Practice, 20(4-5), pp. 579-585.

BNP2TKI (2018) Data Penempatan dan Perlindungan TKI Periode Bulan Desember Tahun 2017 [Online]. BNP2TKI. Tersedia dalam: <http:// www.bnp2tki.go.id/uploads/data/data_17012018_080337_Laporan_Pengolahan_Data_BNP2TKI_2017_1.pdf> [Diakses 18 Februari 2019].

Christie, D. A. (2016). Upaya Indonesia dalam Menangani Pendidikan Anak Tenaga Kerja Indonesia di Sabah Malaysia. eJournal Ilmu Hubungan Internasional, 4(4), pp. 1161-1176.

Handayani, P. (2014). Perjanjian Bilateral Indonesiadengan Malaysia terhadap Tenaga Kerja Indonesia (TKI). Lex Jurnalica, 11(1), pp. 30-35.

Hardiawan, D. (2018). The Impact of Expenditure Inequality and Socioeconomic on Crime Rates in Indonesia. Cross Sectional Study Using Spatial Econometrics and Geographically Weighted Regression. ASSEHR, Bandung.

Hidayat. (2017). Perlindungan Hak Tenaga Kerja Indonesia di Taiwan dan Malaysia dalam Perspektif Hak Asasi Manusia. Jurnal HAM, 8(2), pp. 105-115.

Humana. (2015). Humana Child Aid Society Sabah [Online]. Humana Child Aid Society Sabah. Tersedia dalam: <www.humanachildaidsociety. org> [Diakses 8 Februari 2019].

Humphreys, D. (1996). Regime Theory and Non-Governmental Organisations: The Case of Forest Conservation. The Journal of Commonwealth $\mathcal{E}$ Comparative Politics, 34(1), pp. 90-115.

Insani, F. (2015). Upaya Indonesia Membebaskan Tenaga Kerja Indonesia Terpidana Hukuman Mati di Arab Saudi (2011-2013). Jom FISIP, 2(1), pp. 1-13.

Johnson, E. \& Prakash, A. (2007). NGO Research Program: A Collective Action Perspective. Policy Sciences, 40(3), pp. 221-240.

KBRI Kuala Lumpur. (2018). Profil Pusat Kegiatan Belajar Masyarakat Community Learning Center (CLC) untuk Mendidik Anak-Anak Indonesia di Malaysia Timur. Kuala Lumpur: KBRI Kuala Lumpur. 
Keck, M. E. \& Sikkink, K. (1998) Activists beyond Borders: Advocacy Networks in International Politics. Ithaca \& London: Cornell University Press.

Kwiatkowski, L. (2005). NGOs, Power, And Contradiction In Ifugao, The Philippines. Urban Anthropology and Studies of Cultural Systems and Worls Economic Development, 34(4), pp. 385-436.

Lewis, D. J. (1997). NGOs, Donors, and the State in Bangladesh. The Annals of the American Academy of Political and Social Science, 554(1), pp. 3345.

Meilinda, R. (2017). Latar Belakang Pencabutan Moratorium Tenaga Kerja Indonesia (TKI) ke Malaysia Tahun 2011. Program Studi Ilmu Hubungan Internasional Universitas Airlangga, 6(3), pp. 1-14.

Motlagh, J. (2013). Palm Oil for the West, Exploitation for Young Workers in Malaysia [Online]. The Atlantic. Tersedia dalam: <https://www. theatlantic.com/international/archive/2013/04/palm-oil-for-thewest-exploitation-for-young-workers-in-malaysia/274769/> [Diakses 20 Mei 2019]

Ohanyan, A. (2009). Policy Wars for Peace: Network Model of NGO Behavior. International Studies Review, 11(3), pp. 475-501.

RSPO (2008) Humana Child Aid Society, Sabah [Online]. Roundtable on Suatainable Palm Oil. Tersedia dalam: <https://www.rspo.org/file/ acop2017/submissions/humana\%20child\%20aid\%20society\%20sabah-ACOP2017.pdf> [Diakses 8 Mei 2019]

Thomas, B. K., et al. (2010). Confronting or Complementing? A Case Study on NGO-State Relations from Kerala, India. Voluntas: International Journal of Voluntary and Nonprofit Organizations, 21(3), pp. 358-370.

Yovinus. (2016). Prospek Kerja Sama Bilateral Indonesia-Malaysia bagi Kesejahteraan Masyarakat di Wilayah Perbatasan. Dinamika Global , $1(2)$, pp. 24-43. 